\title{
LA CONTROVERSIA DEL ARA DE VICTORIA
}

\author{
The Controversy of Victoria's Altar \\ Ignacio Jesús ÁLVAREZ SORIA ${ }^{1}$ \\ Universidad de Zaragoza
}

\section{Resumen}

El artículo trata sobre las ideas de tolerancia, igualdad, legitimidad y libertad religiosa en la Tardoantigüedad, tomando como ejemplo la discusión surgida en torno al altar de Victoria, que evidencia también las relaciones de las autoridades paganas y cristianas con el poder imperial. A través de esta discusión podremos ver los argumentos y peticiones utilizados por ambas partes, que en muchas ocasiones coinciden con los discursos que tenían antes de que cambiasen las tornas y el cristianismo se convirtiese en una religión hegemónica en el Imperio Romano.

Palabras clave: Símaco, Ambrosio, Imperio, religión, tolerancia, Tardoantigüedad

\section{Abstract}

The article is about the ideas of religious tolerance, equality, legitimacy and liberty in the Late Antiquity with the example of the controversy of Victoria's altar. This controversy also evinces the connection of Pagan and Christian authorities with the imperial power. Through this dispute, we can know the arguments and requests used by both parties; which usually agree with the reasons that the contrary had before Christianity became the dominant religion in the Roman Empire.

Keywords: Symmachus, Ambrosius, Empire, religion, tolerance, Late Antiquity

En el presente artículo centraremos nuestra atención en las ideas de tolerancia, igualdad y legitimidad en materia religiosa en la Tardoantigüedad, un aspecto interesante porque permite conocer mejor el cómo y el porqué

1 Graduado en Historia y Master en Ciencias de la Antigüedad por la Universidad de Zaragoza. Correo electrónico: 629657@unizar.es. Fecha de recepción del artículo: 29 de octubre de 2016. Fecha de aceptación: 1 de diciembre de 2016.

$\overline{\text { STVDIVM. Revista de Humanidades, } 22 \text { (2016) ISSN: 1137-8417, pp. 13-35 }}$ 
de que en el Imperio Romano acabó por imponerse el cristianismo como religión hegemónica y no se alcanzó un tratamiento igualitario entre los cultos. Todo ello ejemplificado con la controversia surgida en torno al Ara de Victoria, que nos proporciona una preciosa documentación para intentar alcanzar estos objetivos.

En estas páginas analizaremos los escritos de Símaco y San Ambrosio relacionados con el tema que nos ocupa, es decir, en el caso del primero la Relatio III y en el del segundo las Cartas 17 y 18 ; trabajando con las traducciones de José Antonio Valdés Gallego para el informe de Símaco y de Eustaquio Sánchez Salor, A. D. Lee y José Luis Moreno Martínez para los escritos de San Ambrosio.

\section{Símaco y San Ambrosio}

\subsection{La controversia del Ara de Victoria}

El debate sobre el Ara de Victoria ${ }^{2}$ tuvo tal resonancia que veinte años después de que acaeciese, Aurelio Prudencio (un antiguo funcionario hispano) le dedicó su obra Contra Symmachum. Según Moreno Martínez, este altar se había convertido a finales del siglo IV d. C. en objeto de escándalo para los cristianos y punto de referencia para los practicantes de los cultos tradicionales. Además, la decisión de Graciano de retirarlo de la Curia despertó el sentimiento pagano, cuyos defensores intervinieron en favor del altar y del mantenimiento del culto tradicional de Roma. ${ }^{3}$

En este sentido, Peter Brown señala que el período romano tardío, con el elemento esencial del éxito de la Iglesia apoyada por lo emperadores, estuvo ensombrecido por un aumento de la intolerancia religiosa, especialmente desde finales del siglo IV d. C., debido a prédicas y estallidos de violencia contra otros cristianos, judíos y seguidores de los cultos tradicionales. Además, durante mucho tiempo, los cristianos consideraron que simplemente con no participar en los ritos paganos no se contaminaban espiritualmente, por lo que estos podían seguir existiendo; no obstante,

2 Un altar colocado en la Curia por Augusto en 31 a. C. tras la victoria de Actium y donde se hacían ofrendas al inicio de las sesiones del Senado. Fue retirado en 357 d. C. por Constancio II, repuesto probablemente por Juliano y vuelto a suprimir por Graciano en $382 \mathrm{~d}$. C.

3 José Luis Moreno Martínez, «Aurelio Prudencio y el debate sobre el Altar de la Victoria», Kalakorikos, 7 (2002) pp. 80-82. 
obispos como San Ambrosio de Milán intimidaron a los laicos para reducir las parcelas de tolerancia. No podemos olvidar que, según este mismo autor, en los siglos IV y v d. C., en el Imperio Occidental, la exhortación cristiana podía constituir una nueva forma de poder susceptible de ser utilizada por las elites; es más, un hombre al servicio del dios cristiano estaba vinculado directamente con los sectores acomodados y al mismo tiempo con todos los habitantes del Imperio, como muestra el ejemplo del propio San Ambrosio. ${ }^{4}$

Sin embargo, según Liliana Pégolo, la actuación pagana en relación con el mantenimiento de los cultos no tenía por qué significar un intento de oponer el paganismo al cristianismo triunfante; por el contrario, podía ser la evidencia de ritos familiares vigentes entre las elites romanas, que no conllevaban necesariamente una militancia religiosa, sino, quizás, la búsqueda de la conservación de los bienes simbólicos de la cultura clásica. Además, esta misma autora, recoge la idea de Solmsen de que esta posición mantenida por parte de las élites tradicionales se fundaba en la idea de mantener la «memoria de los antepasados» como sustento ideológico de su poder, el cual no era exclusivamente religioso, sino también económico y social. $^{5}$

\subsection{Símaco y los defensores del culto tradicional}

Quinto Aurelio Símaco Eusebio, uno de los protagonistas de este fenómeno, nació alrededor del 340 d.C. y era hijo de Lucio Aurelio Avianio Símaco Fosforio, que ocupó la Prefectura de la Urbe entre 364 y 365 d.C., y de una hija de Fabio Titiano, Praefectus Urbi en 340 d.C. Su abuelo paterno era Aurelio Celsino, que también fue Prefecto de la Ciudad en 341-42 y en 351, y su bisabuelo fue Marco Aurelio Nerio Símaco, vicario de Macedonia en 318-19 y senador; procedente de una familia de rango senatorial probablemente desde la dinastía Severa. Quinto Aurelio Símaco Eusebio fue cuestor y corrector de Lucania y Brucio en 365, en 369 fue elegido por el Senado para presentar el aurum oblaticum a Valentiniano I con ocasión de sus Decenalia, pudiendo deberse esta elección a que ya había ganado fama como orador pese a su juventud. Fue enviado a la campaña contra los

4 Peter Brown, Authority and the Sacred, Cambridge, Cambridge University Press, 1995, pp. XI y 18-19.

5 Liliana Pégolo, «Historia memoria y conversión en Contra Symmachum de A. Prudencio Clemente», Anales de Historia Antigua, Medieval y Moderna, 40 (2008), pp. 2 y 5.

$\overline{\text { STVDIVM. Revista de Humanidades, } 22 \text { (2016) ISSN: 1137-8417, pp. 13-35 }}$ 
alamanes como comes tertii ordinis y entre 373 y 375 ocupó el cargo de procónsul de África, donde consiguió gran popularidad. En 382 fue enviado por el Senado ante Graciano para abogar por la restitución del Altar de Victoria $^{6}$ en la curia romana, pero la influencia de San Ambrosio sobre el Príncipe (o de Macedonio, jefe de la "cancillería», según José Antonio Valdés Gállego, ${ }^{7}$ que a su vez se basa en lo afirmado por Doménico Vera en su Commento Storico alle Relationes) impidió que la audiencia tuviera lugar.

En julio de 384, fue nombrado Praefectus Urbi y su mandato acabó en enero o febrero de 385; el período en el que ocupó este puesto estuvo marcado por la negativa a la instalación del Altar de Victoria, petición para la que redactó la relatio que va a ser parte del objeto de este estudio, y el ascenso de la influencia cristiana. Para entender su deseo de abandonar el cargo que ostentaba, a lo dicho debemos unir la muerte de Praetextato en diciembre de 384, el líder pagano más notable del momento, que había llegado a ocupar la Prefectura del Pretorio de África, Italia e Iliria, y los crecientes ataques de sus enemigos; así como, la declarada oposición a su persona de los oficiales con los que debía trabajar.

Después se retiró a Campania, pero en 387 acudió a Milán a celebrar el tercer consulado de Valentiniano II y también apoyó a Máximo en su usurpación. Más adelante fue designado para el consulado de 391 e intentó volver a situar el Altar de Victoria en el edificio del Senado aprovechando las desavenencias entre el emperador Teodosio y San Ambrosio, aunque no tuvo éxito y pronto ambos personajes se reconciliaron. De nuevo apoyó una usurpación, la de Eugenio, pero este fue derrotado tempranamente y Símaco se retiró a sus propiedades, aunque fue llamado por el Senado en 395 para organizar el abastecimiento de Roma, porque una carestía estaba causando revueltas preocupantes. Por último, posiblemente intentó que se repusiera la antedicha Ara en 402 pero fracasó y poco después murió. ${ }^{8}$

El cargo de Praefectus Urbi conllevaba mucho poder y prestigio, pues era el culmen de la carrera senatorial, siendo el delegado del poder imperial en Roma, ya que el rango de cónsul era meramente honorífico. El prefecto

6 Aunque no ostentaba ningún cargo político, lo que demuestra su autoridad moral dentro de este organismo. Como aparece en J. P. Callu, Symmaque, V, Discours-Raports, Paris, Société d'édition Les Belles Lettres, 2009, pp. XL-XLI.

7 Quinto Aurelio Símaco, Informes-Discursos, introducciones, traducción y notas de José Antonio Valdés Gallego, Madrid, Gredos, 2003, p. 37.

8 R. H. Barrow, Prefect and Emperor. The 'relationes' of Symmachus. 384 a.D., London, Oxford University Press, 1973, pp. 9-12. 
era el guardián de la ciudad y el responsable del buen funcionamiento de la misma; su principal función era la de administrar justicia y vigilar el cumplimiento de la ley, así como supervisar las reuniones del Senado, la administración de los departamentos gubernamentales italianos, el mantenimiento de los subsidios alimenticios y el buen funcionamiento de los juegos, los trabajos públicos y el culto tradicional. Además, debía informar al emperador de lo deliberado por el Senado y lo realizado por los magistrados, y también era el encargado de comunicar al emperador el sentir de la población, expresada, por ejemplo, en las aclamaciones y entusiasmos pronunciados en el Circo; del mismo modo, era el canal entre el Emperador, el Senado y la población. Sin embargo, su labor no era sencilla, pues las fronteras de su autoridad no estaban bien delimitadas y era fácil cometer excesos, a lo que se unía la dificultad en la aplicación de la ley o la interpretación de algunos rescripta. Por consiguiente, sus actos estaban bajo constante vigilancia por parte de oficiales nombrados por el emperador, que podían elevar quejas directamente el magister officiorum o al Prefecto del Pretorio; entre ellos el vicario, dependiente de la prefectura del pretorio y que tenía su propio tribunal y personal a su servicio, por lo que era un rival potencial, o, en ocasiones, un comes enviado con la misión especial de vigilar la conducta del Prefecto de la Urbe. Finalmente, al ser un nombramiento dependiente directamente de la Corte, era la opinión del emperador la que podía ayudar o defenestrar a un prefecto. ${ }^{9}$

En esta época, Roma ya no era la capital del Imperio, ni tampoco un centro comercial o de producción importante; por el contrario, dependía de la importación de los bienes imprescindibles. No obstante, mantenía la mayoría de sus prerrogativas políticas, su brillo propio y era una referencia espiritual, no solo pagana, sino también cristiana. La ciudad del Tiber conservaba sus órganos de gobierno específicos, de los cuales el superior era el Praefectus Urbi, y entre los que destacaba el Senado, que seguía reuniendo a la elite tradicional. ${ }^{10}$

En este sentido, Peter Brown señala que Símaco era el prototipo de un miembro de la nobilitas del siglo IV d. C., caracterizado por la conjunción de prestigio, cultura y el desempeño de un alto cargo. Esa noción de noble$\mathrm{za}$, al mismo tiempo, era una frontera impuesta por las estrategias matrimoniales, pues «intermarriage was the secret of their vast fortunes». Ade-

9 Ibídem, pp. 1-3.

10 Quinto Aurelio Símaco, Informes-Discursos..., pp. 10-11. 
más, muchas de esas familias habían ascendido con Septimio Severo y sus descendientes, y, como él, eran de origen africano y/o tenían sus principales posesiones en África, Sicilia y el sur de Italia. Por otra parte, este mismo autor hace hincapié en que las cartas e informes de Símaco permiten realizar un seguimiento de su vida y a través de ella, de los contactos que mantenía con las altas esferas de poder del Imperio, ya fueran burócratas, cortesanas, militares o, simplemente, personas con acceso al entorno del Emperador. Esta estrategia de mantener una tupida red de relaciones personales fue una maniobra común dentro de las élites de esta época y las anteriores, aunque el enfrentamiento entre el cristianismo y los cultos tradicionales la alteró. ${ }^{11}$

Respecto a este enfrentamiento, del que la polémica del Ara de la Victoria que nos ocupa es un ejemplo excepcional, el mismo Peter Brown asegura que realmente Símaco no era un pagano propiamente dicho, sino un adorador de los dioses a la forma tradicional, que buscaba que se mantuviera la forma antigua de la religión, al menos para los simpatizantes de la misma. Pero las creencias religiosas no eran la cuestión que le preocupaba, no era una disputa por un sentimiento genuino y personal, sino por la defensa de los intereses de sus amigos. Es más, respecto al cristianismo, su idea de tolerancia parecía fundamentarse en una gran distancia; no obstante, buscó establecer relaciones con algunos obispos, pero no en tal que dirigentes religiosos, sino en su calidad de líderes locales.

$\mathrm{Al}$ mismo tiempo, este autor afirma que las elites tardorromanas buscaban mantener las instituciones y rituales que habían heredado de un pasado que no había sido hollado por el cristianismo. En este sentido se expresa A. H. M. Jones cuando argumenta que el cristianismo encontró más resistencia entre la elite que entre los grupos populares por su nivel educativo, así como por el hecho de que las antiguas familias senatoriales se sentían descendientes de los magistrados y sacerdotes republicanos, por lo que se creían herederos y guardianes de las tradiciones romanas, de manera que era difícil que considerasen demonios a los dioses paganos, como se esforzaban en afirmar los cristianos. ${ }^{12}$

11 Peter Brown, Through the eye of a needle, Princenton, Princeton University Press, 2012, pp. 93-95, 100-101 y 102-103.

12 Como se cita en Arnaldo Momigliano, ed., The conflict between paganism and christianity in the fourth century, London, Oxford University Press, 1963, pp. 19-21. 


\subsection{San Ambrosio y la postura cristiana}

San Ambrosio vivió entre 340 y 397, fue educado en retórica y elocuencia romana, llegó a ser gobernador de Aemilia y Liguria, con sede en Milán, y en 374 fue ordenado obispo de esa misma ciudad. San Ambrosio pertenecía a la aristocracia romana y conocía bien la legislación del Imperio; así mismo, poseía prestigio ante el pueblo y su consejo fue escuchado, con altibajos, por los emperadores Graciano, Valentiniano II y Teodosio I. En esta ocasión intervino ante Valentiniano II para abogar por el rechazo de la petición de Símaco de reinstalar el Altar de Victoria, para ello parece que tuvo acceso al informe enviado por el Prefecto de la Ciudad y escribió las Cartas 17 y 18, que posteriormente analizaremos, en las que trató de contestar cada uno de los argumentos de Símaco. Posteriormente, en 389, ante el nuevo requerimiento elevado por este prohombre pagano a Teodosio, repitió los mismos argumentos en la Carta $57 .{ }^{13}$

Por aquel entonces, Milán se había convertido en una de las ciudades más importantes del Imperio Occidental, alzándose como epicentro efervescente de una notable vida política, económica, religiosa y cultural. Precisamente, la importancia de esta localidad supuso que la actividad pastoral de su obispo, San Ambrosio, se impregnase de un contenido político-religioso, cuyo mensaje fue apoyado por importantes notables en la Corte para hacer frente a las presiones arrianas y paganas; pues la propuesta política de moderación y firmeza cristianas contrastaba con la brutalidad de los soldados bárbaros, influenciados por el arrianismo, el paganismo de la elite y la heterogeneidad causada por la multitud de minorías religiosas, que reclamaban cierta libertad religiosa. ${ }^{14}$

De nuevo, Peter Brown argumenta que en las décadas finales del siglo IV el cristianismo se impuso como religión mayoritaria del Imperio; en ese momento «las comunidades cristianas deseaban un imperio "cristiano", purgado de la onerosa herencia de los dioses y gobernado por un monarca que compartiera sus prejuicios contra los judíos, herejes y paganos». En aquella época, el Imperio continuaba existiendo como comunidad de ciudades, en las que los obispos cristianos jugaban un papel esencial, pues influían sobre

13 Eustaquio Sánchez Salor, Polémica entre cristianos y paganos, Madrid, Akal/Clásica, 1986, p. 22. José Luis Moreno Martínez, «Aurelio Prudencio...», pp. 86-87.

14 Andrea Carandini, Cracco Lellia Ruggini y Andrea Giardina, L'età tardoantica. 2, I luoghi e le culture, en Arnaldo Momigliano y Aldo Schiavone, dirs., Storia di Roma, vol. 3, Torino, Einaudi, 1993, pp. 107-108. 
amplias capas de población que podían reaccionar con iniciativas violentas; por ello emperadores como Teodosio se aliaron con estos movimientos, de profundas raíces en numerosas ciudades del Imperio. No obstante, ya Constancio II (que retiró el antedicho altar ya en 357), según Hugo Zurutuza, «estaba seguramente convencido de que la unidad de la Iglesia era el factor decisivo para la unidad del Imperio y para la paz social que debía establecer en el mundo romano", una unidad y una paz que podían amenazar los cultos tradicionales y otras variantes del cristianismo. En este sentido, el profesor Brown señala que obispos como San Ambrosio creían que iban a comparecer ante Cristo en el Juicio Final para responder de los pecados de sus ciudades, por ello actuaron enérgicamente contra aquello que consideraban contrario al cristianismo. Para alcanzar sus objetivos buscaban la ayuda de los emperadores; como ejemplo claro, tenemos nuevamente a Teodosio, durante cuyo reinado los paganos y herejes se vieron cada vez más desposeídos de sus derechos cívicos y forzados a rendirse a las exigencias eclesiásticas. Además, esos mismos obispos aseguraban que el emperador cristiano debería responder ante Cristo por las almas de sus súbditos. ${ }^{15}$

A estas ideas deberíamos añadir las que defiende Arnaldo Momigliano. En primer lugar, los paganos tenían dificultad para hallar argumentos en apoyo de una conexión racional entre su religión y su política, frente a unos cristianos que no tenían problemas para identificar una monarquía unitaria con el culto a un único dios (tal y como habían argumentado Orígenes y Eusebio); pese a que la doctrina de la Trinidad hizo cuestionable la teología política del Imperio Romano, dificultando la continuidad de la idea de la monarquía divina y dando lugar a multitud de divisiones. En segundo lugar, el impensable resurgimiento del paganismo con Juliano, quien se esforzó en destruir los argumentos en los que se había apoyado la alianza entre el monoteísmo y la monarquía, puso en guardia a las autoridades cristianas contra cualquier posible reforzamiento o consolidación pagana, a la vez que hacía repensar a los teólogos cristianos el providencialismo del Imperio. ${ }^{16}$

A este respecto, Peter Brown agrega que, ante intentos como el de Símaco de mantener los cultos tradicionales, los obispos cristianos reaccio-

15 Peter Brown, El mundo en la antigüedad tardía, Madrid, Taurus, 1989, pp. 125-129. Hugo Zurutuza, «La intolerancia religiosa de Constancio II: algunas puntualizaciones sobre el exilio de los adversarios», Ilu. Revista de Ciencias de las Religiones, 18 (2007), p. 116.

16 Arnaldo Momigliano, De paganos, judíos y cristianos, México, Fondo de Cultura Económica, 1987, pp. 244-258. 
naron firmemente, como con las Cartas de San Ambrosio o La Ciudad de Dios de San Agustín, sometiendo el mito de Roma a un proceso de estudio y cambio profundo, considerándola ciudad santa solo en el plano cristiano, pues allí reposaban los restos de San Pedro y San Pablo; consiguiendo la supremacía en ese plano mítico pese a que la idea de la Roma Aeterna era un legado directo del patriotismo latino. No obstante, en el siglo IV, hombres como Símaco defendían ese patriotismo al considerar a la ciudad como santa y al defender que los ritos paganos habían garantizado el éxito del imperio, por lo que Símaco apeló a emperadores cristianos para que Roma continuase siendo tolerada como «oasis» pagano, a lo que se oponían las autoridades cristianas. ${ }^{17}$

Para comprender esta preminencia de la Iglesia, Arnaldo Momigliano indica que la elite comenzó progresivamente a jugar un papel más decisivo en la Iglesia, puesto que esta surgió en el siglo IV como una organización comparable a la estatal y empezó a considerarse como un mecanismo atractivo para educar e influenciar a la población. Frente a esto, el Estado ni previó ni pudo competir con el poder de la organización eclesiástica. Por consiguiente, en la Iglesia, según este autor, se congregaron las mentes más capacitadas del momento que lograron unir la teología cristiana con la filosofía profana. De manera que la superioridad en dinamismo y eficiencia del cristianismo sobre el paganismo era evidente en el siglo IV, pues los cristianos podían adaptarse mejor a la nueva situación política y social y tratar mejor con los bárbaros. ${ }^{18}$

A este respecto, J. F. Jordán Montes señala que la aristocracia y los funcionarios iniciaron pronto una tendencia de adaptación y aceptación de la preeminencia del cristianismo, ya que la conversión facilitaba una posición social y económica más influyente y acomodada. Como consecuencia, los cultos paganos sufrieron una recesión que determinó un debilitamiento de sus expresiones y el cierre o destrucción material de sus templos, a lo que debemos unir la crisis económica de numerosas provincias, la quiebra del sistema urbano, la escasa preparación de los habitantes del medio rural para perpetuar los ritos oficiales - que mantuvieron encendida por más tiempo la llama de los cultos tradicionales- y el declive interno de los valores clásicos. ${ }^{19}$

17 Peter Brown, El mundo en la..., pp. 145-146.

18 Arnaldo Momigliano, ed., The conflict between..., pp. 9 y 15.

19 J. F. Jordán Montes, «La pervivencia del paganismo en el reinado de Honorio (395-423 d.C.)», en Antonino González Blanco, F. Javier Fernández Nieto y José Remesal Rodrí- 
La visión sobre la relación entre Símaco y San Ambrosio puede desvirtuarse si únicamente tenemos en cuenta los escritos que van a ser estudiados; pero los autores recogen hipótesis como que quizás tuvieran alguna relación de parentesco y, ciertamente, eran amigos de juventud y se guardaron respeto mutuo incluso después de este enfrentamiento, como muestran las ocho cartas de Símaco dirigidas a San Ambrosio (todas ellas de recomendación y escaso interés histórico para esta investigación $)^{20}$ o el hecho de que fuese el propio Símaco quien recomendase a San Ambrosio como profesor de retórica para San Agustín en 384. ${ }^{21}$

\section{ANÁlisis: Relatio III y CARTAS 17 y 18}

\subsection{La Relatio III}

Como se ha dicho anteriormente, en este escrito, Quinto Aurelio Símaco Eusebio pidió al emperador Valentiniano II la reposición del Altar de Victoria en el edificio del Senado y al mismo tiempo la restauración de los derechos y prerrogativas de los cultos tradicionales y sus sacerdotes, que habían sido el uno retirado y los otros suprimidos por el emperador Graciano, el hermano del Príncipe antedicho y al que este autor presenta como víctima de malos consejeros. Se trata del texto más celebre y estudiado de Símaco, pues es un memorial tan vehemente, con un tono exhortatorio y polémico, que está mucho más próximo a una pieza oratoria que a un informe de un oficial dirigido a su superior. La elocuente defensa de la tradición romana y de la libertad de cultos chocó con la intransigencia de un cristianismo triunfante, representado por San Ambrosio, quien consagró específicamente a este asunto las Cartas 17 y 18 y volvió a recordar su posición en la Consolación por la muerte de Valentiniano II (19-20) y la Carta 57, dirigida al emperador Eugenio, que, aunque cristiano, se mostraba complaciente con los cultos tradicionales.

Símaco comienza $(1)^{22}$ señalando que actuaba como portavoz del Senado y se complacía y felicitaba a los príncipes porque hubieran sometido los

guez, eds., Antigüedad y cristianismo, VIII, Arte, sociedad, economía y religión en el bajo imperio y la antigüedad tardia, Murcia, Universidad de Murcia, 1991, pp. 184-185.

20 José Luis Moreno Martínez, «Aurelio Prudencio..., pp. 83 y 93.

21 A. D. Lee, Pagans E christians in late antiquity: A sourcebook, London-New York, Routledge, 2000, p. 196.

22 Con estos números hemos señalado cada uno de los fragmentos que competen a las ideas expresadas, tanto en el caso de Símaco como en el de San Ambrosio.

$\overline{\text { STVDIVM. Revista de Humanidades, } 22 \text { (2016) ISSN: 1137-8417, pp. 13-35 }}$ 
desmanes de la población a la ley (lo que posiblemente hiciera referencia a un decreto imperial que impulsaba la investigación de los expolios sufridos por los templos paganos) ${ }^{23}$. No obstante, expuso que anteriormente se le había impedido tener una audiencia con el difunto emperador Graciano, al que no se responsabiliza del hecho, sino a alguno de sus consejeros u oficiales (episodio al que hemos aludido anteriormente), pues lo calificaba de «divino», como insiste al final de su informe (20). Seguidamente (2), reiteró que escribía como portavoz público por encargo oficial y al mismo tiempo como mensajero de las peticiones de los ciudadanos, esforzándose en resaltar la idea de unanimidad, indicando que lo hacía por el cauce oficial y no mediante intrigas en la corte imperial, (no obstante, la existencia de intrigas e intereses que jugaban en el entorno de los Príncipes permitían achacarles a estos las decisiones que podían considerarse injustas, en vez de a los propios Emperadores). De este mismo fragmento es reseñable la frase «No es lícito hacer nada contrario a la tradición de nuestros padres», pues permite vislumbrar el pensamiento que Símaco defendió con este escrito y que analizaremos más adelante.

Precisamente, la idea de la unanimidad dentro del Senado y entre los ciudadanos vuelve a mostrarse en el punto 5 , cuando dice que «aquella ara guarda la concordia de todos, aquella ara está en armonía con la fe de cada uno y nada otorga más autoridad a nuestras resoluciones que el hecho de que el estamento lo decida todo como quien ha realizado un juramento...». No obstante, San Ambrosio manifestó su discrepancia, argumentando que quienes defendían estas ideas eran realmente una minoría pagana que actuaba en nombre de la institución, compuesta principalmente por cristianos.

El pensamiento tradicional de la religión romana, al que habíamos aludido anteriormente, se presenta en la frase que dice: «Somos precavidos con respecto al futuro y evitamos los portentos producidos por cambios de situación»(3), así como cuando dice «Está además el interés, que es lo que más une al hombre con los dioses», pues estos habían llevado a Roma al éxito y a la victoria (como resalta en el punto 9 con la frase que Símaco pone en boca de Roma, recurriendo a la prosopopeya: «Este culto sometió al orbe a mis leyes»), frase que aparece junto a otra en el punto 8 que dice que «además, si un tiempo prolongado da prestigio a los cultos, debemos preservar una fe de tantos siglos y seguir a nuestros padres, que venturosa-

23 Quinto Aurelio Símaco, Informes-Discursos..., p. 36.

$\overline{\text { STVDIVM. Revista de Humanidades, } 22 \text { (2016) ISSN: 1137-8417, pp. 13-35 }}$ 
mente siguieron a los suyos». Del mismo modo, señala un aspecto fundamental de la religión romana en el punto 10, cuando dice: «Rogamos que haya paz para los dioses patrios», que podemos relacionar directamente con la Pax Deorum; una paz que también se ve alterada, según él, por las disposiciones que perjudicaban a las vestales y a los sacerdocios tradicionales, tal como dice en el punto 14 que con ellas «dañamos al Estado, al que nunca ha convenido ser ingrato», pues, según el esquema tradicional de pensamiento religioso, estas alteraciones serían dañinas para el Imperio. Tal y como expone poco más adelante, en el punto 15, cuando argumenta que «de hechos de esta clase han surgido todas las calamidades de la raza romana [...] Ha seguido a este hecho el hambre del pueblo y una cosecha dañada», idea que se refuerza con las palabras: «La cosecha se ha agostado por el sacrilegio». (16)

Este pensamiento religioso tradicional romano, según el profesor Scheid, basaba la idea de piedad en el cumplimiento escrupuloso de los ritos prescritos; por tanto, no era necesario un sentimiento íntimo, sino solo el respeto riguroso de la tradición cultual transmitida por los mayores. ${ }^{24}$ Según este autor, estos ritos traslucían y suscitaban un sistema de pensamiento, por lo que la infracción de las prescripciones trastornaba la expresión espiritual de los mismos. Por consiguiente, al igual que la conducta piadosa hacía posible la conducta espiritual y la vida armoniosa, la impureza generaba el rechazo público para castigar al impío, siendo perseguido o reprendido por la comunidad en lo profano. Esto ocurría porque suponía una amenaza para todos, no por la falta a la divinidad, pues se consideraba que esta podía tomarse su venganza personal, sino porque había manchado a la comunidad, por lo que esta ofrecía sacrificios expiatorios en su propio nombre. Además, puesto que esa ruptura de la Pax Deorum - concebida como un trato de do ut des con los dioses, que se fundamentaba precisamente en el cumplimiento ritual — se verificaba mediante prodigios (de los que habla Símaco en el punto 3, como las carestías y malas cosechas que nombra en el punto 15) o el fracaso de una misión. A esto debemos unir que, en la medida en que el espacio político y religión se confundían, no era de extrañar que fueran los magistrados los encargados de regular las relaciones del populus con los dioses, de la misma manera que regulaban las relaciones con otras ciudades y con los particulares. ${ }^{25}$

24 Cic. Nat. D. 3.5; 3.6; 3.7; 3.9 y Cic. Har. Resp. 18.

25 John Scheid, La religión en Roma, Madrid, Ediciones Clásicas D.L., 1991, pp. 9-22.

STVDIVM. Revista de Humanidades, 22 (2016) ISSN: 1137-8417, pp. 13-35 
No obstante, fundamentando nuestra visión en esa idea de pureza ritual, no debemos concluir que la religión romana estaba cerrada a las influencias externas, pues, como expuso Jean Bayet:

Roma vivió durante once o doce siglos dentro del conservadurismo obstinado de los ceremoniales y sacerdocios de los comienzos, pero integrando, en el curso de un desarrollo orgánico, todo tipo de cultos extranjeros. Así se multiplicaron las variaciones de un sentimiento religioso que mantuvo, sin embargo, su continuidad hasta el triunfo del cristianismo. ${ }^{26}$

En referencia a la conservación ritual, es destacable la referencia a la situación anterior, al reinado de Valentiniano I (19) que, según Amiano Marcelino, estuvo marcado por una clara política de tolerancia en materia religiosa. ${ }^{27}$ Pero también de Constancio II, del que, aunque prohibió los sacrificios a los dioses paganos bajo pena capital en 356 y retiró el Altar de Victoria en $357,{ }^{28}$ Símaco dice que:

7. [...] no sustrajo ninguno de sus privilegios a las vírgenes sacras, proveyó a los nobles de sacerdocios, no rechazó el desembolso de las ceremonias romanas y [...] contempló con placido semblante los santuarios, leyó los nombres de los dioses inscritos en los frontones, preguntó por los orígenes de los templos, manifestó su admiración por los fundadores y, aunque personalmente él era seguidor de otros cultos, preservó estos para el Imperio.

Respecto a este asunto, Peter Brown señala que este informe debe considerarse como la búsqueda de un viejo consenso entre paganos y cristianos dentro del Senado, en el que cada uno podía tener sus creencias y se respetaban los ritos tradicionales $(3,8)$. Sin embargo, las medidas aplicadas sobre las vestales y los sacerdotes pueden no considerarse un ataque a las posiciones paganas, sino un intento de igualar los sacerdocios tradicionales a la situación del clero cristiano, cuya posición se había debilitado con Valentiniano I, lo que podría suponerse beneficioso en caso de buscarse una situación de igualdad y tolerancia de cultos. No obstante, en Roma dichas medidas fueron vistas como una agresión directa a una venerable institución que actuaba por el bien público, por ello Símaco escribió a la Corte. ${ }^{29}$ Para apoyar esa idea de respeto y tolerancia, Símaco esgrimió,

26 Jean Bayet, La religión romana: Historia política y psicológica, Madrid, Cristiandad, 1984, p. 17.

27 Amiano Marcelino, Historia, 30.9.5.

28 Quinto Aurelio Símaco, Informes-Discursos..., p. 41.

29 Peter Brown, Through the eye..., pp. 104-105. 
entre otros, un argumento - que fue duramente contestado por San Ambrosio- cargado de influencias neoplatónicas que dice así: «¿Qué importancia tiene con qué doctrina indague cada uno la verdad? no se puede llegar por un solo camino a un secreto tan grande». (10)

En relación con los sacerdocios, las vestales y el culto a Vesta, que solo podían practicar siendo vírgenes, eran considerados como garantes de la estabilidad y seguridad del Estado. ${ }^{30}$ Las medidas tomadas contra estas sacerdotisas, que consistían en la eliminación del estipendio que se les entregaba cuando se retiraban de sus funciones; además de su inmunidad fiscal y de su capacidad para recibir herencias (13). Privilegios estos últimos que sí poseía el clero cristiano, hecho que se contrapondría a la idea de la igualación de Peter Brown. A favor de estas medidas argumentó San Ambrosio, como veremos más adelante. Pero, Símaco se pregunta sobre el beneficio económico de las mismas, afirmando que el buen príncipe no debía caer en la codicia (avaritia), arrancando antiguos subsidios, puesto que el beneficio iba a ser mínimo, ni en la crueldad (crudelitas), por agraviar a quien sufre la pérdida; ambas características del tirano, arquetipo con el que se puede vislumbrar una identificación del emperador por su actuación (12), aunque a priori le resta toda responsabilidad.

\subsection{La Carta 17}

Ante el escrito enviado por Símaco, San Ambrosio respondió con dos cartas en las cuales presenta al Cristianismo como culmen de la bondad de todas las cosas. En primer lugar, San Ambrosio escribió la Carta 17, en la que explicaba al emperador Valentiniano II que la petición no fue realizada por todo el Senado, sino por una minoría, que dar culto a Victoria en el Senado era una injuria y una presión para los senadores cristianos, que debía oponerse a la solicitud de Símaco para ser fiel a su fe cristiana, porque de lo contrario no sería recibido en la Iglesia y también porque debía guardar fidelidad a su padre y a su hermano.

San Ambrosio hacía hincapié en que, al ser un emperador cristiano, Valentiniano II debería dejar clara su fe y actuar en consecuencia con entusiasmo, no aceptando la petición de Símaco de restaurar el altar y man-

30 Por ello, las escasas vituallas públicas que recibían tenían un fuerte significado: «the Vestals' share in the annona represented the perpetual sacred Exchange between the earth and the gods, which ensured the protection of the empire and of the stupendous human settlement of Rome». Peter Brown, Through the eye..., p. 106. 
tener con fondos públicos los sacrificios a los dioses paganos (3). San Ambrosio recuerda, además, la actuación de los paganos durante el reinado de Juliano, pues habían denegado a los cristianos la tolerancia que en ese momento reclamaban y habían destruido iglesias; por otra parte, aboga por negarles los privilegios porque pueden conducir por un mal camino al querer aprovecharse de ellos, por ejemplo, para evitar las cargas públicas (4). Sin embargo, no parece defender la intolerancia, sino que apoya el derecho a la defensa y práctica de las propias convicciones cuando dice que «cada cual debe defender con libertad y guardar fielmente la creencia de su alma» (7); por lo que parece animar al príncipe a defender sus convicciones, y también considerar el apoyo estatal como diferenciador, aunque su ausencia, en el caso de los cultos tradicionales, sería nefasta, pues religión tradicional y Estado eran inseparables. De manera que, el Altar de Victoria fue objeto de rechazo porque, como los senadores cristianos se veían obligados a actuar contra sus convicciones, atentaba contra la libertad religiosa que poseían todos los ciudadanos (11).

Por otra parte, San Ambrosio amenazaba veladamente a Valentiniano II - recordemos que era un niño de apenas 13 años-, afirmando que atender al requerimiento pagano sería cometer sacrilegio, por lo que le animó a rechazar la petición si no quería arriesgarse a la excomunión. También parece asegurar que los cristianos velaban por la fe del emperador y le conminaba a no dejarse convencer por una minoría de senadores paganos que se arrogaban la palabra de toda la institución, como ya hemos señalado anteriormente; idea que ya había formulado el obispo de Roma, San Dámaso, cuando le había escrito con ocasión de la petición de 382 para mostrarle el malestar de los senadores cristianos y su rechazo a la petición respecto del altar de Victoria. A lo que añade que debería respetarse la decisión de su hermano Graciano, que fue firme en su rechazo (10).

También lo amenazó con la no cooperación de los obispos — que, como hemos dicho antes, prácticamente eran engranajes esenciales para el funcionamiento del Imperio - si la decisión era contraria a sus intereses; animando a Valentiniano II a continuar por la senda marcada por su contemporáneo Teodosio (13). Este rechazo eclesiástico estaría motivado por la equiparación de la religión cristiana con el resto de cultos, dando el mismo trato a Cristo que a lo que llama «ídolos», pues, como dijo el mismo Cristo «uno no puede servir a dos amos». Por otra parte, en cuanto a las vestales, preponderaba a las vírgenes cristianas, que no recibían ningún tipo de contraprestación, ni privilegio por parte del Estado, por lo que revocar esa decisión significaría dar preferencia a los paganos, irritando a los cristianos (14). 
Además, expone claramente a Valentiniano II que cuando estuviera ante Cristo no podría alegar su edad para protegerse de la condena que lo esperaba si tomaba la decisión equivocada (15). Finalmente, recuerda que debe rendir homenaje a su padre y a su hermano en materia religiosa, para conseguir también la salvación (17).

\subsection{La Carta 18}

Probablemente, la petición de la Relatio III fue rechazada tras la Carta 17, pero San Ambrosio escribió después la Carta 18, en la que contestaba a cada uno de los argumentos del Praefectus Urbi.

En cuanto al mantenimiento de los cultos tradicionales, criticó la afirmación que puso Símaco en boca de Roma, pues consideraba que los ritos tradicionales no salvaron a Roma ni de los galos ni de Aníbal, sino que en esas ocasiones mostraron su ineficacia, llegando a ridiculizar lo que los paganos consideraban como intervenciones divinas y a afirmar que los dioses de Aníbal y los de los romanos eran los mismos, por lo que su intervención no habría sido determinante a no ser que luchasen contra ellos mismos y hubieran sido al mismo tiempo vencedores y vencidos (4-6).

Además, negó cualquier utilidad de los sacrificios, pues las guerras las ganaba el valor de los hombres y el resultado dependía de la voluntad de Dios, cuyo parecer no cambiaría con el derramamiento ritual de sangre de animales inocentes (7). Por otra parte, frente al argumento misoneísta que Símaco ponía en boca de la personificación de Roma, según el cual era una injuria y una vergüenza arrepentirse y cambiar en la ancianidad, San Ambrosio contrapone la idea de que siempre es bueno deplorar los errores y tomar la senda de la bondad (7); idea que enlazaría con la tradición pragmática romana, que asimilaba lo nuevo a lo práctico (23).

Frente al argumento de los diversos caminos que conducen a la verdad que expuso Símaco, San Ambrosio esgrime la idea de que los paganos ignoran lo que los cristianos han aprendido del mismísimo Dios, y lo que ellos buscan mediante conjeturas, los cristianos lo poseen con certeza; por lo que los métodos de encontrar la verdad no coinciden. Además, a continuación señala lo que parece considerar la inutilidad de los dioses paganos, pues necesitaban que sus fieles pidieran la paz para ellos ante el emperador mientras los cristianos pedían por la paz del emperador a su dios; por otra parte, critica la adoración ante imágenes, pues dice que los cristianos lo consideran una injuria (8). 
En cuanto al asunto de las vestales, critica que los paganos no puedan concebir la virginidad gratuita, tal y como hacen los cristianos, confiando al dinero lo que no se confía a la virtud; remarcando también la escasa importancia que pueden tener en número y la poca seriedad que se puede demostrar si tan solo es temporal. Frente a ellas, como hemos dicho anteriormente, destaca a las vírgenes cristianas, de proverbial pobreza, sencillez y humildad, así como su sacrificio. De manera que consideraba que la virginidad de las sacerdotisas de Vesta no era auténtica virtud e integridad, pues se hacía con ánimo de lucro, que en si ya creía que era una amenaza para la castidad. Además, indica que si ellas debían recibir un dinero del Estado, también debían hacerlo las vírgenes cristianas, lo que indica que no parece no tener en cuenta es la prohibición de ser beneficiarios de testamentos de los sacerdotes paganos, que limitaba sus posibilidades económicas (11-12). Igualmente, comparaba a los clérigos cristianos con los sacerdotes paganos, llegando a una conclusión parecida que en el caso de las vírgenes, es decir, que los cristianos no recibían dinero público, destacando el hecho de que estos empleaban sus bienes para atender a los pobres (13-16). Por consiguiente, reclamaba bajo el gobierno de príncipes cristianos lo que los cultos tradicionales y su clero tuvieron bajo emperadores paganos (12).

Por último, San Ambrosio puso de manifiesto que los paganos, que defendían los ritos tradicionales, no hubiesen tenido problemas para aceptar cultos extranjeros, los dioses de ciudades vencidas (30). En ese sentido, puesto que, según Arnaldo Momigliano, el politeísmo romano era capaz de adaptarse y de confundirse con las tradiciones provinciales, en él rara vez se planteaban cuestiones de creencia, sino que primaba el principio de actuar correctamente, lo que comprometía a la elite dirigente en la conservación de la tradición religiosa. ${ }^{31}$

Además, consideraba que la victoria no era una divinidad, sino un don que Dios concedía a las legiones y no estaba bajo la potestad de la religión tradicional (30). Por otra parte, argumenta frente a la idea de la hambruna como castigo divino que las malas cosechas habían estado focalizadas en algunos lugares del imperio y que no eran un fenómeno excepcional (17-21).

31 Arnaldo Momigliano, De paganos..., p. 207.

$\overline{\text { STVDIVM. Revista de Humanidades, } 22 \text { (2016) ISSN: 1137-8417, pp. 13-35 }}$ 


\section{Conclusiones: Paganos y CRistianos}

A finales del siglo IV y comienzos del $\mathrm{v}$, los paganos exigieron a los cristianos la misma condescendencia y talante liberal que los propios cristianos habían reclamado cuando eran perseguidos y atacados desde posiciones oficiales. Por otra parte, las acusaciones de abandono de las tradiciones romanas o el olvido de los dioses que encumbraron a Roma entroncaban con la idea de que los cristianos eran los culpables de los desastres que sufría el Imperio. Hemos de tener en cuenta que la filosofía pagana acusaba a la doctrina cristiana de ser nueva, de no tener la antigüedad que tenían las religiones de otros pueblos, así como de no haber contribuido al engrandecimiento del Imperio Romano; igualmente, culpaba al cristianismo de los males que aquejaban al orbe romano y desconfiaba de este por ser una doctrina dividida por multitud de sectas y por su falta de respeto a los emperadores y al poder constituido, al menos hasta el conocido como Edicto de Milán. ${ }^{32}$

El profesor Sánchez Salor incide en que para los paganos anticristianos el apogeo del Imperio se debía a sus dioses; como consecuencia, cuando las gentes empezaron a abandonar sus cultos, estas divinidades se olvidaron de Roma y esta comenzó su decadencia. De manera que la religión cristiana sería la culpable de la decadencia del Imperio. Esta idea se apoya en la defensa de las antiguas costumbres, de los ritos, del eclecticismo religioso romano. Por su parte, la defensa de los cristianos se centró en demostrar que el encumbramiento del Imperio fue obra de su dios, que el eclecticismo romano era ridículo y que los desastres fueron mayores antes de la venida de Cristo. También es cierto que los cristianos argumentaban que la historia de Roma había sido una serie de crímenes e impiedades y estaba cargada de superstición, ridiculizando los elementos básicos de la religión tradicional, como los augurios, que consideraban producto de los demonios. Argumentos que hemos podido vislumbrar en los textos analizados en el presente artículo. ${ }^{33}$

Además, durante la polémica, como hemos podido comprobar, la historia se convirtió en instrumento de ataque, en un arma de combate; pues en buena medida se trataba se contraponer las visiones milenaristas y apocalípticas, que interpretaban como inmediato el libro del Apocalipsis, y el legado mítico de la Roma Aeterna, de origen pagano y mantenido oficial-

32 Eustaquio Sánchez Salor, Polémica entre..., pp. 11-13.

33 Ibídem, pp. 193-194.

$\overline{\text { STVDIVM. Revista de Humanidades, } 22 \text { (2016) ISSN: 1137-8417, pp. 13-35 }}$ 
mente, aunque, como hemos señalado anteriormente, transformado y retomado por el cristianismo una vez había adquirido dimensión institucional y empezaba a considerar la historia de Roma como un precedente providencial y necesario para su éxito. ${ }^{34}$

Ese mismo hecho trajo un cambio en las posiciones cristianas, según $\mathrm{H}$. Bloch, pues, tras las persecuciones y una vez apoyada por los nuevos gobernantes cristianizados, la Iglesia pasó a la ofensiva en las décadas finales del siglo V. ${ }^{35}$

Con relación a la idea de libertad religiosa, Mar Marcos señala que la obra de Tertuliano constituye un ejemplo sin parangón, puesto que «Tertuliano es el primer autor de la Antigüedad que reclamó la libertad religiosa, considerándola además como un derecho natural del individuo»; no obstante, las premisas de libertad y voluntariedad que defendía para que el acto religioso tuviera validez eran extrañas a la mentalidad y a la praxis de la religión romana. Como se ha indicado anteriormente, la religión no era una cuestión de creencias, sino de lealtad familiar y cívica. Por el contrario, esta autora destaca que el cristianismo:

[...] supuso una transformación radical en la identidad religiosa del individuo y del mundo antiguo. No era una religión étnica, sino decididamente universal, que exigía un compromiso personal reflexivo más allá de la pertenencia a un pueblo o una polis, así como la adhesión total del iniciado, que debía renunciar a cualquier otra forma de actividad y a todo un estilo de vida; su monoteísmo exclusivista, por otra parte, lo hacía incompatible con cualquier otro sistema religioso. ${ }^{36}$

Frente al carácter cívico y social de las religiones politeístas, el cristianismo exigía una participación activa y comprometida, una conversión que implicaba el abandono de una comunidad que compartía una identidad religiosa y la entrada en otra con otra identidad y unos límites nuevos.

No obstante, de nuevo esta autora apunta que fueron las persecuciones las que provocaron la primera reflexión en cuando a la ilegitimidad de la coacción en materia religiosa y las ventajas de la persuasión: puesto que los cristianos necesitaban de la tolerancia al ser una minoría perseguida, desa-

34 Andrea Carandini, Lellia Cracco Ruggini y Andrea Giardina, L'età tardoantica..., p. 715.

35 Recogido en Arnaldo Momigliano, ed., The conflict between..., p. 193.

36 Mar Marcos, «La idea de libertad religiosa en el Imperio Romano», Ilu. Revista de Ciencias de las Religiones, 18 (2007), pp. 62-65. 
rrollaron una retórica de libertad sobre argumentos que no eran específicamente cristianos, sino que eran encontrados en los principios que regían la praxis política del Imperio en materia religiosa. Por lo tanto, la libertad religiosa que otorgaba el Edicto de Milán se fundamentaba en el concepto de Pax Deorum, en el derecho de la divinidad a ser adorada y en la conveniencia para los súbditos de hacerlo libremente, de manera similar al Edicto de Galerio. Pero también tomaba algunos elementos ajenos a la mentalidad romana tradicional, como la toma en consideración del derecho de los individuos a hacer una elección religiosa personal. No obstante, el final de las persecuciones cambió radicalmente el discurso de los intelectuales y las autoridades en materia religiosa, demostrando que la idea de tolerancia no había sido interiorizada, o quizás que el reinado de Juliano supuso un cambio de actitud fundamental en este asunto; de manera que a finales del siglo IV, fueron los intelectuales paganos como Símaco quienes retomaron ese discurso de tolerancia, aunque también bajo la presión de una situación adversa: el abandono por parte del Estado del vínculo con los cultos tradicionales y la amenaza de leyes muy severas contra quienes siguieran practicándolos. ${ }^{37}$

Atendiendo a los hechos, A. D. Lee incide en la deriva de intolerancia, que comienza cuando en 382, Graciano, el hijo y sucesor de Valentiniano I, renunció aparentemente a la jefatura de la religión tradicional, eliminando de su nomenclatura el título de Pontifex Maximus, que Constantino y sus sucesores habían mantenido. Este hecho simbólico estuvo acompañado de unas medidas prácticas contra las que luchó Símaco, centrando el foco en el simbólico Altar de Victoria. Mientras que en las provincias orientales, al cuidado de Teodosio, los templos paganos eran destruidos sin represalias; el culmen de ese fenómeno fue el incendio del Serapeion de Alejandría en 391 o 392. No obstante, las expresiones de resistencia pagana fueron comunes, como la usurpación de Eugenio en 390 (cuya derrota a manos de Teodosio fue considerada simbólicamente como la manifestación del juicio de Dios), unidas en muchas ocasiones a profecías sobre el fin del cristianismo. Sin embargo, las décadas finales del siglo IV trajeron el comienzo de la cristianización de las zonas rurales del Imperio, donde habían permanecido más arraigadas las formas de culto tradicionales. ${ }^{38}$

37 Ibídem, pp. 73-81.

38 J. F. Jordán Montes, «La pervivencia del paganismo..., p. 185; A. D. Lee, Pagans E christians..., pp. 111-112. 
Otro hecho reseñable fue que, para Jordán Montes, según el Codex Theodosianus, los paganos podían ser excluidos de ciertos derechos, como el de testar, y fueron despojados de antiguos privilegios y exenciones, siendo también apartados de algunos cargos y vetada su posibilidad de expresarse religiosamente. Pese a todo, las prácticas paganas no fueron perseguidas o castigadas levemente por la connivencia de las autoridades, bien porque conocían la escasa relevancia de estas actividades o porque despertasen cierta simpatía, o quizás para evitar conflictos innecesarios; por lo que con el tiempo se produjo un sincretismo en muchos sectores de la sociedad romana, en ocasiones ya cristiana, con fenómenos de contaminación y prestamos mutuos. Un ejemplo claro es el que expone el profesor Brown, pues con la prohibición de los sacrificios, el culto pagano continuó en forma de procesiones, banquetes públicos y grandes juegos, al tiempo que en Roma, los senadores paganos y cristianos convivían realizando los ritos correspondientes y participando en los grandes espectáculos de raíz pagana - situación que había defendido Símaco desde la Prefectura de la Urbe-, que no eran necesariamente una reliquia del pasado, sino una alternativa a la versión cristiana del Imperio. ${ }^{39}$

De manera que la proposición de Símaco reflejaba el sentir de la aristocracia pagana, es decir, la vuelta a la antigua religión y el respeto a las costumbres por ser elementos que habían probado su funcionalidad para el Estado, que no debe considerarse como una reliquia del pasado sino como una alternativa a la versión cristiana del Imperio. Este sentir remitía al principio de tolerancia religiosa frente a una Iglesia cada vez con más prestigio y poder dentro del Imperio ya cristianizado, con capacidad para orientar las actuaciones y las decisiones políticas. A esto último debemos añadir que hubo paganos que siguieron ocupando puestos de gran responsabilidad o de relevancia en el Imperio, como el propio Símaco, cónsul en 391 en Occidente y Tatiano en Oriente. ${ }^{40}$

A modo de cierre, retomo una de las ideas y palabras de Peter Brown respecto a la polémica:

Symmachus's memorandum was turned down, and Ambrose's reputation rose yet further in Christian circles. But the real winner was the emperor. An autocrat in a distant court, Valentinian II made clear, in his rejection of

39 Ibídem, pp. 186-189. Peter Brown, Through the eye..., p. 103 y 93.

40 Andrea Carandini, Lellia Cracco Ruggini y Andrea Giardina, L'età tardoantica..., pp. 760761; Arnaldo Momigliano, ed., The conflict between..., p. 197. 
Symmachus's memorandum, that he did not need to dependent either on the Senate or in ancient rituals performed in Roma to be sure of the unique and still numinous protection of Victory. ${ }^{41}$

\section{REFERENCIAS BIBLIOGRÁFICAS}

BARrow, Reginald Haynes, 1973, Prefect and Emperor. The 'relations' of Symmachus. 384 a.D. London, Oxford University Press.

BAYET, Jean, 1984, La religión romana: Historia política y psicológica, Madrid, Cristiandad.

Brown, Peter, 1989, El mundo en la antigüedad tardía. Madrid, Taurus.

BRown, Peter, 1995, Authority and the Sacred. Cambridge, Cambridge University Press.

Brown, Peter, 2012, Throught the eye of a needle. Princenton, Princeton University Press.

Callu, Jean Pierre, 2009, Symmaque, V, Discours-Raports. Paris, Société d'Édition Les Belles Lettres.

Carandini, Andrea, Lellia Cracco Ruggini y Andrea Giardina, 1993, L'età tardoantica. 2, I luoghi e le culture. Vol. 3 de Arnaldo Momigliano y Aldo Schiavone, dirs., Storia di Roma. Torino, G. Einaudi.

JORDÁN MONTES, Juan Francisco, 1991, «La pervivencia del paganismo en el reinado de Honorio (395-423 d.C.)» En Antonino González Blanco, F. Javier Fernández Nieto y José Remesal Rodríguez, eds., Antigüedad y cristianismo. VIII. Arte, sociedad, economía y religión en el bajo imperio y la antigüedad tardia. Murcia, Prensas de la Universidad de Murcia: 183-199.

LEE, A. D., 2000, Pagans and christians in late antiquity: A sourcebook. London-New York, Routledge.

Marcos SÁnCHEZ, María del Mar, 2007, «La idea de libertad religiosa en el Imperio Romano». Ilu. Revista de Ciencias de las Religiones, 18 (2007): 61-81.

Momigliano, Arnaldo, ed., 1963, The conflict between paganism and christianity in the fourth century. London, Oxford University Press.

Momigliano, Arnaldo, 1987, De paganos, judios y cristianos. México, Fondo de Cultura Económica.

Moreno Martínez, José Luis, 2002, "Aurelio Prudencio y el debate sobre el Altar de la Victoria». Kalakorikos. Revista para el estudio, defensa, protección y divulgación del patrimonio histórico, artístico y cultural de Calaborra y su entorno, 7 (2002): 79-102.

41 Peter Brown, Through the eye..., p. 108. 
PÉgolo, Liliana, 2008, «Historia, memoria y conversión en Contra Symmachum de A. Prudencio Clemente». Anales de Historia Antigua, Medieval y Moderna, 40 (2008): 153-164.

SÁnChez SAlor, Eustaquio, 1986, Polémica entre cristianos y paganos. Madrid, Akal/Clásica.

SCHEID, John, 1991, La religión en Roma. Madrid, Ediciones Clásicas.

Símaco, Quinto Aurelio, Informes-Discursos. [Introducciones, traducción y notas de José Antonio Valdés Gallego.] Madrid, Gredos-Biblioteca Clásica Gredos, 2003.

ZurutuZA, Hugo, 2007, «La intolerancia religiosa de Constancio II: algunas puntualizaciones sobre el exilio de los adversarios». Ilu. Revista de Ciencias de las Religiones, 18 (2007): 115-125. 